\title{
NO CORAÇÃO DA MODERNIDADE: A AVENTURA PESSOANA
}

\author{
IN THE HEART OF MODERN: THE ADVENTURE OF PESSOA
}

\author{
Maria Helena Nery Garcez \\ Universidade de São Paulo
}

\begin{abstract}
RESUMO: Este artigo tem por objetivo a reflexão sobre as maneiras pelas quais se registra no Livro do Desassossego, do semi-heterônimo pessoano Bernardo Soares, a inquietação que lhe provocavam as questões estéticas. A partir do exame das observações que o ajudante de guarda-livros faz acerca de suas obras e autores prediletos, das poéticas que mais admira, daquela de que se sabe próximo, das grandes obras que critica, franqueando-nos, por assim dizer, as portas de sua oficina literária e permitindo ao leitor desvendar seus processos de despersonalização, aqui se pretende observar atentamente como o desassossego que move sua escrita não se limita ao campo da metafísica, mas dá relevante destaque ao fenômeno estético. Central, nessa tarefa que assumimos, é a investigação da relevância, na escrita de Soares, da reflexão sobre a dialética da obra imperfeita e da obra perfeita, vista por ele como uma "tragédia"; nesse particular, examinaremos sua proximidade com o tratamento dado ao tema por Antero de Quental e Mário de Sá-Carneiro, que também, a seu modo, se ocuparam da tragédia do voo de Ícaro, do desejo frustrado da perfeição.
\end{abstract}

PALAVRAS-CHAVE: Fernando Pessoa, Bernardo Soares, poesia, $O$ livro do desassossego, estética.

ABSTRACT: This paper aims to reflect about the ways through which the Livro do desassosego, written by Fernando Pessoa's semi-heteronym Bernardo Soares, registers the anxieties provoked in him by aesthetical questions. By examining the observations the bookkeeper's helper makes about his literary works and his favored authors, the poetics he admires, including the one he knows himself to be closer, the great works he criticizes, opening to us, so to speak, the doors of his literary workshop and letting the reader discover his processes of depersonalization, here we intend to observe closely how the disquiet that moves his writing doesn't limit itself to metaphysics, but highlights the aesthetical phenomenon. It is central, in this task, the investigation of how relevant it is, in Soares works, the thinking about the dialectics of the imperfect and the perfect work, seen by him as a "tragedy"; in this particular regard, we will exam his proximity with the treatment given to this theme by the poets Antero de Quental e Mário de Sá-Carneiro, whom also, each in his own way, wrote about the tragedy of Icarus' flight, the frustrated desire of perfection.

KEYWORDS: Fernando Pessoa, Bernardo Soares, Portuguese poetry, $O$ livro do desassossego, aesthetics

O Livro do Desassossego, do semi-heterônimo Bernardo Soares, está impregnado de textos sobre a escrita, a poesia e a prosa, a criação artística. O desassossego de 


\section{Revista do SELL}

v. $4, n^{\circ} .2$

ISSN: $1983-3873$

Bernardo Soares é compósito, apresenta muitas facetas e uma delas é a reflexão inquieta, muitas vezes dolorosa e ansiosa, sobre questões de estética. Erraria quem julgasse que seu desassossego seria essencial ou exclusivamente metafísico no sentido estrito do termo, ou melhor, acertaria quem nesse desassossego incluísse uma grande dose devida às questões relativas à arte. O ajudante de guarda-livros da Rua dos Douradores fala-nos de suas obras e autores prediletos, das poéticas que mais admira, daquela de que se sabe próximo, critica grandes obras, abre-nos as portas de sua oficina literária, desvenda-nos seus processos de despersonalização. Alguma coisa desses aspectos constituirá a matéria desta exposição.

Para principiar, chamo para aqui um trecho do fragmento 291 da edição do Livro do desassossego segundo Richard Zenith. Reproduzo o trecho que pode constituir uma espécie de longa epígrafe destas reflexões e seu ponto de partida:

Se houvesse na arte o mister de aperfeiçoador, eu teria na vida uma função...

Ter a obra feita por outrem, e trabalhar só em aperfeiçoá-la... Assim, talvez, foi feita a llíada...

Só o não ter o esforço da criação primitiva!

Como invejo os que escrevem romances, que os começam, e os fazem, e os acabam! Sei imaginá-los, capítulo a capítulo, por vezes com as frases do diálogo e as que estão entre o diálogo, mas não saberia dizer no papel esses sonhos de escrever, (2011, p.283)

Aquele para quem Fernando Pessoa reserva a designação de semi-heterônimo por julgar que o estilo com que ele escreve não se diferencia muito do seu, confessa encontrar dificuldades para criar obras de fôlego como são os romances. Já no fragmento 289, havia afirmado que amava alguns "poetas líricos porque não foram épicos ou dramáticos, porque tiveram a justa intuição de nunca querer mais realização do que a de um momento de sentimento ou de sonho. (...) É perfeita a lírica de Heine, e todo o drama - de um Shakespeare ou de outro - é imperfeito sempre". (2011, p.282).

Não estará nessa assertiva, pergunto, uma possível razão pela qual, na obra pessoana, existam personagens que recitam seus monólogos dramáticos sem estarem inseridos numa ação, ou, formulando a questão de outro modo, se a criação dos heterônimos o torna um poeta dramático, não é verdade que as Ficções do interlúdio não constituem um poema dramático como normalmente entendemos o sentido desse termo? Da mesma forma, pergunto ainda, não estará nessa assertiva uma razão pela qual Mensagem é um poema épico-lírico ou lírico-épico, mas simplesmente não é um poema épico? É claro que a mescla de gêneros - típica da modernidade - pode constituir uma resposta para as indagações feitas, mas não será essa mescla de gêneros o resultado de um reconhecimento da grande dificuldade e até mesmo da impossibilidade de "poder construir, erguer um Todo, compor uma coisa que seja como um corpo humano, com 


\section{Revista do SELL}

v. $4, n^{\circ} .2$

ISSN: $1983-3873$

perfeita correspondência nas suas partes, e com uma vida, uma vida de unidade e congruência, unificando a dispersão de feitios das suas partes!"? (2011, frag. 289, p.282) Será que das congeminações estéticas de Bernardo Soares (no caso da última citação, de raiz tão aristotélica e também goetheana), associadas ao que recebemos da obra pessoana como nos chegou realizada, não podemos deduzir uma sua opção por "nunca querer mais realização do que a de um momento de sentimento ou de sonho"? Segundo ele, ainda no mesmo fragmento, "Nenhum drama de Shakespeare satisfaz como uma lírica de Heine" (2011, frag. 289, p.282) e, apesar de Fernando Pessoa - bem como Bernardo Soares - em vários de seus escritos manifestar notável apreço pelos grandes poetas construtores, ele só trabalhou para ser construtor na exígua, embora brilhante, arquitetura da Mensagem. É muito provável que estivesse em seus planos arquitetar a publicação do jogo heteronímico, pois disso tratam numerosos papéis de seu espólio, mas "erguer esse Todo", essa construção, foi um projeto que, se ele várias vezes esboçou em papel, nunca chegou a efetivamente realizar.

Bernardo Soares gostaria, então, de ser um "aperfeiçoador", de não ter o "esforço da criação primitiva", mas de "trabalhar só em aperfeiçoá-la". Conta-nos a respeito de seus projetos:

A llíada que compus teve uma lógica de estrutura, uma concatenação orgânica de episódios que Homero não podia conseguir. A perfeição estudada dos meus versos por completar em palavras deixou pobre a precisão de Virgílio e frouxa a força de Milton. (...) E quantos Horácios fui!

E sempre que me levantei da cadeira onde, na verdade, estas coisas não foram absolutamente sonhadas, tive a dupla tragédia de as saber nulas e de saber que não foram todas sonho, que alguma coisa ficou delas no limiar abstrato em eu pensar e elas serem.

Fui génio mais que nos sonhos e menos que na vida. A minha tragédia é esta. Fui o corredor que caiu quase na meta, sendo até aí o primeiro.

Seja-nos permitido um aparte talvez maldoso: não é mais fácil ser um "aperfeiçoador" do que "ter o esforço da criação primitiva"? De criticar quase todos somos capazes; criar é que são elas... Mas voltemos ao centro de nossas reflexões.

Vemos no Livro do desassossego a dialética da obra imperfeita e da obra perfeita, cujo resultado Soares, pelo menos três vezes, nestes fragmentos que estou citando, designa por "tragédia" (Cf. frag. 289 e frag. 290). Chega a dizer que perder pai e mãe, amigo, um amor, tudo isso é suportável, mas "o que não se pode suportar é sonhar uma coisa bela que não seja possível conseguir em ato ou palavras” (2011, frag. 289 ,p.282). Sua "tragédia" faz pensar no "Tormento do ideal", de Antero de Quental, faz pensar no conjunto de poemas do livro Dispersão, de Mário de Sá-Carneiro, concretamente no poema "Quase", cujo eu da enunciação é companheiro desse "corredor" de Bernardo 


\section{Revista do SELL \\ v. $4, n^{\circ} .2$}

ISSN: $1983-3873$

Soares, que "caiu quase na meta, sendo até aí o primeiro". Por essa razão dissemos, no início deste texto, que no metafísico desassossego do ajudante de guardador de livros está incluída a tragédia do voo de ĺcaro, do desejo frustrado da perfeição.

Prosseguindo o raciocínio, vejamos agora: "O poema que eu sonho não tem falhas senão quando tento realizá-lo". (2011, frag. 322, p.305). Ficam claros os dois processos: o de sonhar, completamente interior, e o de realizar, ou seja, o de extrinsecar o poema, o de materializá-lo. Bernardo Soares, que no texto "Maneira de bem sonhar nos metafísicos", se autodenomina "o artista supremo, o sonhador como eu o sou" (2001, p.444), que afirma ter chegado a uma vitória tal sobre o sonho que eles lhe trazem sempre o que deseja, coisa que só é dada ao "sonhador aperfeiçoado" (ibidem), verifica que:

Não há obra de artista que não pudera ter sido mais perfeita. Lido verso por verso, o maior poema poucos versos tem que não pudessem ser melhores, poucos episódios que não pudessem ser mais intensos, e nunca o seu conjunto é tão perfeito que o não pudesse ser muitíssimo mais.

Ai do artista que repara para isto! que um dia pensa nisto! Nunca mais o seu trabalho é alegria, nem o seu sono sossego. (...)

E para quê exprimir? O pouco que se diz melhor fora ficar não dito! (frag. 328, p.309)

Não é preciso refletir muito para concluirmos que afinal esta é a condição humana e que o que ajudante de guarda-livros da Baixa deseja é a condição divina. Mais do que o voo de Ícaro, como disse acima, seu elã é adâmico. "Sereis como deuses" foi a promessa da antiga serpente no jardim do Éden e é essa a causa da frustração e das congeminações doridas que percorre tantos e tantos fragmentos de seu livro. Desta polaridade entre a obra ideal e a realizada gera-se o desassossego, como ele deixa implícito na citação acima aludindo à perda do "sossego" de seu sono. Sua tristeza chega a tal ponto que o sonhador avalia o exprimir-se por escrito de forma negativa. Melhor, então, seria não criar. Esta conclusão niilista constitui um motivo temático que perpassa o Livro do desassossego, pois ora Soares considera que é preciso escrever, ora conclui que o melhor seria renunciar a fazê-lo. Num desses fragmentos paradoxais, há revelações importantes:

O único destino nobre de um escritor que se publica é não ter uma celebridade que mereça. Mas o verdadeiro destino nobre é o do escritor que não se publica. Não digo que não escreva, porque esse não é escritor. Digo do que por natureza escreve, e por condição espiritual não oferece o que escreve.

Escrever é objetivar sonhos, é criar um mundo exterior para prémio [?] evidente da nossa índole de criadores. Publicar é dar esse mundo exterior aos outros; mas para quê, se o mundo exterior a nós e a eles é o "mundo exterior" real, o da matéria, o mundo visível e tangível? Que tem os outros com o universo que há em mim? (2011, frag. 209, p.217). 


\section{Revista do SELL}

v. $4, n^{\circ} .2$

ISSN: $1983-3873$

Nesse rebelde fragmento, o semi-heterônimo estava discorrendo sobre o "o facto divino de existir (...)"e o "satânico de coexistir", sobre a relação com os outros. Considera a coexistência um desperdício da própria personalidade, daí concluir que "o verdadeiro destino nobre é o do escritor que não se publica". Se escrever já é "objetivar sonhos, criar um mundo exterior", publicar, então, é pior, é mais grave, é "dar esse mundo exterior aos outros." Segundo Soares "o mundo exterior a nós e a eles é "o mundo exterior" real, o da matéria, o mundo visível e tangível", aquilo que, pelo modo de a ele referir-se, percebe-se que despreza ou até abomina. Tal desprezo pela matéria, pela realidade e pela coexistência com os outros nos leva a perguntar se não será essa a atitude que é satânica, ao revelar uma soberba rebeldia relativamente à condição humana.

Convém ainda não esquecer que o ajudante de guarda-livros da Baixa não está temporalmente tão distante do aristocrático Axel, de Villiers de L'Isle-Adam, personagem do drama homônimo publicado em 1890. Lembremos que Axel propõe a Sara, jovem igualmente aristocrática, por quem está inteiramente enamorado, que se suicidem porque realizar o amor seria destruí-lo. Sara vibra no mesmo diapasão e ambos se envenenam. É o neoplatonismo levado ao extremo, nos finais do oitocentos, e satirizado pelo realista Eça de Queirós no conto “José Matias", de 1897, neoplatonismo que, retomado da Renascença, já havia inspirado o primeiro romance moderno da literatura francesa, $L a$ princesse de Clèves de Mme de La Fayette, obra de 1678. É também o que encontramos no proto-heterônimo queirosiano Fradique Mendes, quando recusa a sugestão de escrever um livro em que narrasse toda a sua viagem à África, respondendo que só poderia produzir formas sem beleza e incompletas, pois não conseguiria plasmar todas suas vivências em palavras. Eça comenta que tal resposta revelava o sentimento que mantivera mudo aquele espírito brilhante - possuído da "sublime ambição de só produzir verdades absolutamente definitivas, por meio de formas absolutamente belas". De fato, há algo de bastante neoplatônico no elitista ajudante de guarda-livros lisboeta que não por acaso algumas vezes ironicamente se retrata às voltas com o livro Razão. Suas opções espiritualistas são estéticas e existenciais.

Esse elitista decadente que é Bernardo Soares recusa-se ao amor, isola-se do outro, vê-se num patamar superior e, igualmente, recusa a realidade exterior, o mundo da matéria. Contudo, como faz ver o filósofo Luigi Pareyson, a obra de arte não pode existir sem uma matéria: 


\section{Revista do SELL \\ v. $4, n^{\circ} .2$}

ISSN: $1983-3873$

A arte é necessariamente extrinsecação física. A presença de um elemento físico é indispensável para a arte, quer ele apareça maciço e evidente como nas pedras da arquitetura, quer ele se atenue até quase desaparecer como nas páginas de um romance, onde 0 aspecto semântico das palavras prevalece sobre sua consistência fonética, sem no entanto cancelá-la de todo. Também a palavra tem um aspecto físico, porque ela é não apenas sentido, mas também som, a ponto de uma poesia, separada daquelas palavras insubstituíveis às quais se confiou, sumir e desaparecer (...) Alguma coisa do valor artístico de uma poesia se colhe também numa língua desconhecida, e muitas vezes se pode estabelecer que na escolha de uma palavra o poeta foi guiado pela previsão de uma determinada pronúncia, ou de uma determinada intensidade, ou até de um determinado timbre (...) (...) o artista não se limita a almejar e sonhar, mas pretende dar vida a uma forma que viva de per si, destacada dele, objeto entre objetos; e ele, que se encontra às voltas com a obra a fazer, bem sabe o quanto lhe pesa, o quanto demora e o quanto o empenha a execução concreta dela (...). ( Pareyson, 1984, p.117-8)

Devido a esse espiritualismo estético exacerbado de que padece o eu da escrita do Livro do desassossego, nele encontramos um fragmento de rebeldia como este:

A sublimidade de desperdiçar uma vida que podia ser útil, de nunca executar uma obra que por força seria bela (...)

Ah, meu amor, a glória das obras que se perderam e nunca se acharão, dos tratados que são títulos apenas hoje, das bibliotecas que arderam, das estátuas que foram partidas. Que santificados de Absurdo os artistas que queimaram uma obra muito bela, daqueles que, podendo fazer uma obra bela, de propósito a fizeram imperfeita, daqueles poetas máximos do Silêncio que, reconhecendo que poderiam fazer obra de todo perfeita, preferiram coroá-la de nunca a fazer. (Se fora imperfeita, vá.)

Quão mais bela $A$ Gioconda desde que a não pudéssemos ver! E se quem a roubasse a queimasse, quão artista seria, que maior artista que aquele que a pintou!

(...)

E eu que digo isto - por que escrevo eu este livro? Porque o reconheço imperfeito.

Sonhado seria a perfeição; escrito, imperfeiçoa-se; por isso o escrevo.

E, sobretudo, porque defendo a inutilidade, o absurdo, [] - eu escrevo este livro para mentir a mim próprio, para trair a minha própria teoria.

E a suprema glória disto tudo, meu amor, é pensar que talvez isto não seja verdade, nem eu o creia verdadeiro. (2011, frag. 330, p.310-311)

Mas, para sermos verdadeiros, devemos dizer que também encontramos outros textos do tipo: "Será má a obra que se não fará nunca. Pior a que nunca se fizer. Aquela que se faz, ao menos fica feita. (...) O que escrevo, e que reconheço mau, pode também dar uns momentos de distração de pior a um ou outro espirito magoado e triste." (frag. 14, p.58)

Como já foi dito, em relação a escrever uma obra de arte, o semi-heterônimo ora diz uma coisa ora o seu contrário. Fica claro que existe certo gosto d'épater le bourgeois, aliado ao gosto do paradoxo. É preciso não ir credulamente atrás de tudo quanto ele diz, como, afinal, também ocorre com os escritos dos outros heterônimos e do ortônimo. Sou do parecer que toda a obra pessoana deve ser lida com cautela, com uma espécie de pé atrás, sem que nunca a ela nos entreguemos ingenuamente. Também mais de uma vez afirma que sua finalidade ao produzir uma obra de arte é distrair-se. (frag.1 e frag.118).

Antes de ir encerrando estas linhas, vale a pena determo-nos num fragmento em que Bernardo Soares diz-nos que, com lucidez e demoradamente, relê tudo quanto 


\section{Revista do SELL}

v. $4, n^{\circ} .2$

ISSN: $1983-3873$

escreveu e chega à conclusão que "tudo é nulo" e mais valera que ele o não houvesse feito (frag. 169, p.183 e 184). Em sua avaliação, diz:

O que me dói é que o melhor é mau, e que outro, se o houvesse, e que eu sonho, o haveria feito melhor. Tudo quanto fazemos, na arte ou na vida, é a cópia imperfeita do que pensámos em fazer. Desdiz, não só da perfeição externa, senão da perfeição interna; falha não só à regra do que deveria ser, senão à regra do que julgávamos que poderia ser. Somos ocos não só por dentro, senão também por fora (...)

Com que vigor da alma sozinha fiz página sobre página reclusa, vivendo sílaba a sílaba a magia falsa, não do que escrevia, mas do que supunha que escrevia! Com que encantamento de bruxedo irónico me julguei poeta da minha prosa, no momento alado em que ela me nascia, mais rápida que os movimentos da pena, como um desforço falaz aos insultos da vida! $\mathrm{E}$ afinal, hoje, relendo, vejo rebentar meus bonecos, sair-lhes a palha pelos rasgos, despejarem-se sem ter sido...

Vemos o ajudante de guarda-livros da Rua dos Douradores na sua oficina de criador, solitariamente fazendo a poesia de sua prosa sílaba a sílaba e ele parece não nos contar nada de novo, isto é, nada que não tenha ainda sido tratado aqui. A obra realizada fica aquém da obra sonhada. Mas há um modo de dizê-lo, uma formulação que acrescenta algo ao que já tinha sido dito outras vezes: "vivendo sílaba a sílaba a magia falsa, não do que escrevia, mas do que supunha que escrevia". O desencanto de Soares Ihe vem de a magia com que criou, de que a magia experimentada no momento da criação, magia que ele qualifica de falsa, não é magia do que escrevia, mas do que "julgava que escrevia!" Fala-nos, o semi-heterônimo, de um engano cruel: no momento da criação, o criador sente o endeusamento de estar criando $\mathrm{X}$, com maiúscula e julga que criou X com maiúscula. Passado algum tempo, ao reler-se, ele encontra um x minúsculo e esvaído, que não é aquele que ele supunha ter criado, mas é como os bonecos que perderam sua palha pelos rasgões. É a dor do endeusamento perdido.

De tanto ver Soares sofrer com essa problemática, ocorreu-me, por contraste, que uma leitura que Ihe serviria de antídoto poderia ter sido o conto "A perfeição" de Eça de Queirós, também de 1897, como "José Matias".

E a fim de não concluirmos em melancolia, vejamos o que sucede no texto "Maneira de bem sonhar nos metafísicos" (pp.443-446). É nele que Bernardo Soares se apresenta como o "artista supremo", um "supremo sonhador". Após fazer o elogio do sonho, discorre sobre o modo de nele aperfeiçoar-se, propondo quatro passos ou graus. No 1 passo, aconselha a ler romances, aprendendo a entregar-se totalmente à leitura, imaginando-se a viver com as personagens; no $2^{\circ}$, deve-se aprender a evitar as sensações físicas de modo real, mas traduzi-las para o nível mental. Trata-se de uma mentalização do gozo; no 3ํ, já o corpo nada sente, toda a sensação é só mental. Deve-se construir sonhos para si mesmo, imaginar um poeta a escrever de um modo e outro a escrever de outro modo. 


\section{Revista do SELL}

v. $4, n^{\circ} .2$

ISSN: $1983-3873$

Não há necessidade de escrever essas imaginações; no $4^{\circ}$ e último grau, criado um quadro com personagens, o sonhador deve vivê-las todas ao mesmo tempo, ser todas essas almas conjunta e interativamente, é o mais alto grau de despersonalização. Qual a conclusão desse processo? Diz ele:

“Este é o único ascetismo possível. Não há nele fé, nem um Deus

Deus sou eu." (p.446)

Bernardo Soares sintetiza a criação heteronímica e, ao fazê-lo deixa ver, mais uma vez, seu ambicioso projeto adâmico: ser o Deus da pequena "humanidade" que cria.

\section{BIBLIOGRAFIA}

PAREYSON, Luigi - Os problemas da estética. Tradução de Maria Helena Nery Garcez,São Paulo, Martins Fontes Editora, 1984.

PESSOA, Fernando - Livro do desassossego. Organização Richard Zenith, 3ª ed., São Paulo, Companhia das Letras, 2011. 